\title{
Fluctuations of particles inside flat-bottomed funnel flow silo
}

\author{
Dangcheng Zhang ${ }^{1}$, Xiaodong Yang ${ }^{1}$, Jinhui Zhan ${ }^{1}$, and Xiaoxing Liu ${ }^{1}$ \\ ${ }^{1}$ Institute of Process Engineering Chinese Academy of Sciences
}

October 22, 2020

\begin{abstract}
In this work the flow behavior of granular material in flat-bottomed funnel flow silos was investigated through 3D Discrete Element Method (DEM) simulations. It is observed that particles in the flowing zone move collectively, manifested by the oscillatory fluctuations of the averaged particle vertical velocity and the non-Gaussian characteristics of the fluctuations of individual velocity around average. The delayed correlations of velocity fluctuation and the Fourier spectrums of velocity and contact force between particles were analyzed to characterize the propagation of flow fluctuation. It is found that there exist two special vertical positions in the converging zone. The lower one corresponds to the emission source from which the velocity wave propagates both upwards and downwards. The higher one locates at the upper boundary of converging zone and is characterized by the most violent fluctuation of contact force. Possible mechanisms of the appearances of these two vertical positions are discussed.
\end{abstract}

\section{Hosted file}

manuscript.pdf available at https://authorea.com/users/369272/articles/488198-fluctuationsof-particles-inside-flat-bottomed-funnel-flow-silo

\section{Hosted file}

figures_table.pdf available at https://authorea.com/users/369272/articles/488198fluctuations-of-particles-inside-flat-bottomed-funnel-flow-silo 